\title{
Adopted vs. Adapted EFL Textbooks in Iranian Context: Focusing on Gender Representation and Teacher Beliefs
}

\author{
Massoud Yaghoubi-Notash \\ English Department, Faculty of Persian Literature \& Foreign Languages, University of Tabriz, Tabriz, Iran \\ Elmira Kooshavar \\ Department of Post-graduate English Language Studies, Payame-Noor University of Teheran, Teheran, Iran
}

\begin{abstract}
Gender, as a socially constructed variable, seems to spread in to every corner of the language classroom including the syllabus. Studies show that most of textbooks are biased in a way that they present stereotypical female images. A gap in literature is disfavoring women by under-representing or linguistically marginalizing females. In the light of this gap, this study has an analytic quantitative comparison of discursive features of conversations in Interchange series (as authentic textbook series) with a nationally produced centralized syllabus for a semi-state control language education in the Iranian context. Results showed an encouraging level of gender fairness in each series and comparing to each other. The EFL teachers' perception about gender representation in the textbooks has been studied in the form of correlational KAP (i.e. knowledge, attitude, practice) survey and the result showed that female teachers scored better in knowledge items and that teachers' overall practice in the classroom is correlated to their attitude more than their knowledge. Implications of the study are discussed.
\end{abstract}

Index Terms -English textbooks, gender representation, biased gender image

\section{INTRODUCTION}

Gender is so naturalized in our life that it has become invisible but at the same time our social life is suffused with gender (Sunderland, 2000a). In every culture or society some specific roles or characteristics are attributed to either men or women, and thus two genders are considered different. Gender differences are, actually, a fundamental fact of sociolinguistic life and it is not surprising that they are reflected in language. In other words, there are certain forms of language which are appropriate only for use by men and other forms which only women may use. "In some cases, these differences depend not only on the ... [gender] of the addresser, but also on the ... [gender] of the addressee" (Ansary and Babaii, 2003, p.1).

Since 1970s, sociolinguists have become interested in the relationship between language and gender, and they consider all the behavioral variations, achievements in foreign languages included, explicable by cultural factors, hence by socially constructed gender differences (Sunderland, 2000b). "Gender spreads into every corner of the language classroom" (Sunderland, 2000a) and this is in accordance with our perception of "gender as something not always apparent but always present" (Sunderland, 2000b, p.203).

Sunderland (2000b, p.205) cites Catalán who states that "gender in contrast with such variables as age, motivation and learning style, is neglected in well-known and widely-cited textbooks on second language acquisition." On the other hand, Female learners experience various sorts of educational disadvantages such as "male dominance in the classroom; differential teacher treatment by gender, by which males get more and better teacher attention than females; and representation in textbooks in which female characters are variously stereotyped, trivialized, or rendered relatively invisible" (Sunderland, 2000a). Language education atmosphere is not in favor of girls either. Along with the various studies on gender and language education, there have been many studies in the last 30 years that showed imbalance in gender representation in language textbooks. Sunderland, Cowley, Rahim, Leontzakou, and Shattuck (2000) cited many 1980s and 1990s studies on ESL/EFL textbooks in which a) males were overrepresented, b) men were likely to take more powerful and greater range of occupational roles than women, c) both males and females were given gender stereotypical roles and activities, and d) in dialogs, females were found to speak less and perform a narrower range of discourse roles, etc. Sunderland et al. (2000) believe that, by having progressive texts in terms of gender representation, teachers' behavior in relation to texts, which is called "teacher talk around the text" or "mediation", should be the focus of newer studies. However, the lack of data from developing countries, where English language teaching is pervasive and where gender and educational opportunities is still the matter of concern, makes gender representation still an intriguing issue to SLA practitioners and researchers.

Gender lies among the social factors which contribute to language learning. Languages may sometimes be seen as a 'girls' subject' because girls, in spite of male dominance, differential teacher treatment and imbalance in textbooks, tend 
to choose languages, and nowadays the female postgraduates in languages outnumber males. In Iran, as well, the results of universities entrance exams, the number of literature and language students, and the number of those attending to language learning institutes, testify that proportionally girls are more than boys in number. Thus, having in mind that everybody in the society should be provided with an equal opportunity for learning, it seems sensible to study imbalance in gender representation in EFL textbooks.

Conversations in ESL/EFL textbooks are chosen to be studied in terms of imbalanced gender representation as they are instances of real life conversations and they can be made use of in different ways in classroom context, i.e. being role played, extended, or personalized by students. In other words, this study attempts to find out to what extent do the conversations in ESL/EFL textbooks marginalize female learners?

By knowing to what extent an EFL textbook is marginalized in favor of either gender, teachers and practitioners can tactfully maneuver their teaching in order to get the best result. On the other hand, Iranian organizations that are in charge of production and publication of EFL materials may use the result in order to make the textbooks less imbalanced in respect of gender representation. The present study specifically addresses whether cross-gender conversations of EFL textbooks used in Iranian outside school English courses portray any kind of imbalance in gender representation quantitatively and in terms of some discourse features?

Scholars believe that gender has a significant role in our social interaction. Research has shown that gender influences our perception of ourselves and others (e.g. Chavez, 2001). Moreover, in the society people's behavior is assessed through gender norms. As Holmes (2006) stated:

One dimension on which we are constantly, if generally unconsciously, assessing people's behavior is that of contextual appropriateness in relation to gender norms. As with all social norms, this is often most evident when a person breaks or challenges the taken-for-granted assumptions about the way women or men 'should' behave. (p.5)

This gender stereotyping or better saying gender roles given by the society to either men or women, has pervaded our lives and is reflected in every corner of the society. "Gender is simultaneously everywhere and nowhere" (Sunderland, 2000a. p.8). Everywhere, because, as human beings, our social experience is intertwined inextricably with gender; and nowhere, because gender is often so taken-for-granted that it becomes invisible. "Because gender is so wide-ranging, it spreads into every corner of the language classroom and indeed of language education" (Sunderland, 2000a. p.8). Therefore there is a need for research in order to raise teachers' and students' awareness of gender issues and to increase the chance of equal education opportunity.

There has always been a debate that educational system is not equal for boys and girls. While one of the objectives of the education is to enable students to realize their capabilities and reach their full potentials, it seems it will not be possible unless in a gender equitable environment where fair opportunities, access, benefits, and resources are provided for both male and female students. In fact, upon entering school, girls perform equally and sometimes better than boys on almost every measure of achievement, but by the time of graduation from high school, they have fallen behind (Sadker and Sadker, 1994). Sunderland (2000a) states that:

Much research on gender and education has focused on different sorts of educational disadvantages experienced by women and girl learners, for example male dominance in the classroom; differential teacher treatment by gender, by which males get more, and arguably better, teacher attention than females; and representation in textbooks in which female characters are variously stereotyped, trivialized, or rendered relatively invisible. (p.8)

A great deal of research on education and gender has been conducted throughout the world and similar results are elicited from them. Swann (2005) reviewed some of those findings that girls and boys had different speaking styles and they wrote in different ways and about different topics; That boys' speaking styles allowed them to dominate classroom interaction, so that girls had less opportunity to contribute; and that textbooks and other resources used in schools contained many more male than female characters and examples. She even introduces some remedies to counteract such imbalances and inequalities.

The policy and practice of education is challenged by a shift in conceptions of language and gender. The postmodern shift, which focuses on gender diversity, on context and performativity and on uncertainty and ambiguity, is being applied to the recent studies of education and gender.

Gender bias in education is an insidious problem that causes very few people to stand up and take notice. Teachers are generally unaware of their own biased teaching behaviors because they are simply teaching how they were taught (Sadker and Sadker, 1994). Female and male students nowadays are receiving separate and unequal educations due to the social generalization that takes place in the schools. Unless teachers are made aware of the gender socialization and the biased messages they are unintentionally imparting to students every day, and until teachers are provided with the methods and resources necessary to reduce gender bias in their classroom, girls will continue to receive an inequitable education (Erden, 2009).

As stated in the previous sections, in first language (FL) settings, males tend to dominate the ground and are more secure and self-confident than females. Similarly in a first language academic environment, male students are reported to perform better and receive more teacher attention and get better grades. In contrast, females are the queens of the realm of language studies, particularly a foreign language. Languages may be seen as female's subjects because girls tend to choose languages; even statistics from academic settings show that females enroll in language courses more than males and female post-graduates in languages outnumber males. Chaves (2001) has given reasons to study gender in the 
foreign language classroom. The first reason she states is that investigations into the role of gender in foreign language can draw on the existing research in first language. Second reason is that, insights from gender studies can be applied in an actual language classroom setting. The third reason for the study of gender is that these studies can serve as a link to the larger area of gender studies. And as the last reason for gender studies she states that "communicative competence is thought to include pragmatic aspects and knowledge of target language sociolinguistic conventions as well as the component of cultural competence. As such, linguistic gender roles in the target language are part of the body of the knowledge to be acquired in the foreign language class, at least at the advanced level" (Chaves, 2001, p.14).

Teachers' perception of gender issues in the classroom affects students' learning. Teachers should always be aware of what goes on in the classroom, what a textbook is going to induce into the minds of students, and how students feel about the textbooks and teaching / learning process. Researches show that teachers' attitudes about gender specific performances of the students can bias their teaching and therefore students' learning.

So teachers' biased perception of students' performance may result in wrong or diverse interpretation. Sunderland et al (2001) explored teacher's influence in the classroom and regarding gender biased textbooks. They name it as 'teacher talk around the text' or teacher's 'mediation of the text' and they believed it may play a role in shaping student response, learning opportunities, and gender identity.

\section{GENDER REPRESENTATION AND STEREOTYPES IN TEXTBOOKS}

The way gender is represented in the textbooks will have an effect on learners' gender identities and language learning opportunities (Sunderland, 2001). Sunderland et al. (2001) reviewed researches in 1970s and 1980s that had performed content analyses of gender representation in foreign language textbooks. These studies found out that males were overrepresented, that men occupied more powerful and greater range of occupational roles than women, that both males and females were represented in stereotypical roles, and that women tended to be stereotypically emotional.

Stereotypical representation of either gender is another issue in the EFL/ESL textbooks. The situation seems less dire as regards gender representation in the textbooks nowadays. It can be a consequence of the change in publishers' and writers' awareness and values, along with those of teachers and students as the consumers of the textbooks (Sunderland et al., 2000). Still textbooks are affluent with gender bias and stereotypical representations of females and males thus a need for research.

\section{A. Imbalance in Gender Representation}

Sunderland (2000a) and Sunderland et al. (2001) believe that gender bias in the texts has influences on gender identity of the learners, language learning opportunities, and teaching/learning process. There are researches that explored gender bias or in other words imbalanced representation of females in the EFL textbooks. Ansary and Babaii (2003) explored the status of sexism in two ESL/EFL textbooks (Right Path to English I \& II) in Iran. They analyzed gender visibility in both texts and illustrations and female/male topic presentation in dialogs and reading passages and found both textbooks completely sexist which underrepresented females. Besides, their qualitative inquiry into genderlinked job possibilities and activities depicted a passive, traditional and stereotypical picture of women which was in contrast with women's stance in Iranian society, especially in urban areas. They concluded that women often appeared less visible than men in the textbooks; that English was basically taught through the presentation of male-orientated topics and females were more visible in indoor passive activities, and were placed in traditional stereotypical roles.

Özdoğru, Aksoy, Erdoğan, and Gök (2004) carried out a content analysis of the presentation of gender roles in Turkish elementary school "Turkish" and "Life Studies" textbooks. Their result is surprisingly very close to that of the Iranian study cited earlier; traditional and indecisive women characters, doing house chores, raising children and, being compassionate, what the authors believed were the traditional Turkish female traits; and self-confident, decisive and adventurous male figures.

Holmqvist and Gjörup (2006) investigated the representation of gender and gender roles in six English textbooks, two of which were published in the 1970s. They analyzed books in terms of gender imbalance within the three categories of authors, occupations, and illustrations and the result showed that there was a tendency in all the textbooks to promote males and diminish females.

Harashima (2004) conducted a quantitative case study on one unit of an EFL textbook and found that the unit in questioned contains a far greater number of male referents than female, male characters preceded the female ones when they are introduced in text or exercises, male characters were more often associated with higher social status than the female ones, and there are some expressions in text and in illustrations which are derogatory towards women.

As are seen from different studies, gender bias and imbalanced gender representation is still common in the EFL/ESL textbooks.

\section{B. Conversations in the Textbooks and Gender Representation}

Conversations and dialogs in EFL/ESL textbooks are of utmost importance especially in a communicative syllabus design. Martha Jones, Catherine Kitetu and Jane Sunderland (1995) stated that:

One 'genre' of a language textbook for which it is possible to hypothesize actual uses in the classroom is the dialogue, i.e. a written or taped conversation between two or more people. Among other ways, a dialogue can be used: 
(a) As an 'oral model', to be demonstrated by two or more students and listened to by other class members;

b) As a basis for oral, pair or group work for the whole class, to be 'parroted' and/or adapted or extended through such activities as role play, simulation or dramatization;

(c) As a model in the textbook which can be extended by the students in writing;

(d) As a model to be read silently in the textbook, or listened to on tape; and

(e) For the oral completion of a gapped conversation (e.g. in a language laboratory, where dialogues can be used by individual students).

These ways can be used alone or in combination. (electronic version)

The question that comes into mind here is: does gender imbalance exist in textbook conversations as it appears to do in language textbooks in general? Very few researches of gender bias in EFL materials have in fact looked at the ways in which the male and female characters in their conversations use language differently, either qualitatively or quantitatively.

Jones et al. (1995) argue the pedagogical implications of gender imbalance in textbook dialogs. They continue that another probable disadvantage of imbalanced gender representation in the textbook dialogs is that it can predispose language learners to make assumptions about the gendered nature of verbal behavior of native speakers of the language they are learning and they may continue to imitate this in class accordingly. Jones and et al. (1995) conducted a quantitative study on the number of male and female characters in the dialogs, the number of times either gender initiated the conversation, and the number of words spoken by either gender. They studied three ESL textbooks which were published between 1987 and 1994. They found that there was some gender bias in the textbook dialogues but on the whole, the bias was not extreme.

As mentioned before, the way teachers and students think of gender representation in textbooks has a great impact on language learning and teaching process. Yepez (1994) studied four teachers behavior in terms of gender biased behavior found in the classroom and concluded that all four teachers put emphasis on gender equity while teaching. The way teachers handle the imbalanced textbooks, and as Sunderland et al. (2001) put it 'consume' the textbook, is very crucial too. So teachers' awareness of imbalanced gender representation in the EFL/ESL textbooks can promote the quality of teaching learning process.

The above mentioned studies show that there is a necessity for research in this area especially in Iranian context. Much work has been done on gender stereotyping in textbooks for foreign language teaching around the world. However, little has focused on the language of conversations, which are a characteristic feature of EFL/ESL textbooks.

\section{METHOD}

After reviewing the relative literature, establishing the framework for gender representation in the textbooks, and going through the relevant theoretical and empirical explanations in the previous chapter, now it is the time for discussing the experiments conducted for this study on examining gender representation in adapted and adopted EFL textbooks and teachers' perception about it.

In this section, the procedure to collect and analyze the data is explained. In other words, this chapter is concerned with the material, participants, methodology, and the process of computing and calculating the data.

In order to answer the two research questions - represented below - this section is divided into two parts.

\section{A. Materials}

Two series of EFL textbooks, which represent adopted and adapted EFL textbooks, are chosen from among many books which are being taught in Iranian private English courses. The representative of adopted textbooks is 'Interchange Third Edition' published by Cambridge University Press, in four volumes including 'Interchange Intro', 'Interchange 1', 'Interchange 2', and 'Interchange 3'. This series will be simply referred to as 'Interchange series' in the rest of this research. The reason for choosing Interchange series is its popularity in EFL institutes in Iran. The representative of adapted textbooks is the latest impression of 'Iran Language Institute (ILI) Series', which is locally produced by ILI as a centralized institute with nationwide branches and is considered one of the popular and respected language institutes in Iran. The reason for choosing this series is that it is the most well-established source, from authorities' point of view, among the books produced and published in Iran. ILI series senior courses include four levels namely 'Pre Intermediate', 'Intermediate', 'High Intermediate', and 'Advanced'. Due to not having any conversations the 'Advanced' books are excluded. There are three books for each level so nine books are examined.

The cross gender conversations in these two series are the targets of this study. The coding method of the conversations and the way some of their discursive features are derived are explained in the following sections.

\section{B. Procedures}

The cross gender conversations in each series are marked and addressed for quick reference. The series are coded for the next analyses. In order to find out how much a series is biased in terms of gender representation, in each series the number of cross gender conversations is counted and their ratio to all the conversations is calculated. Besides, the number of words that each gender used in each conversation is counted. All the words including articles, prepositions, and interjections such as 'wow' or 'oh' are counted as one word. Words with hyphen in between and a person's first 
and last name - if uttered together - are counted as one word. Some conversations in Interchange series has a part which is not displayed in the textbook and are designed for listening comprehension; even these parts are examined through their transcripts in the teachers' book.

From among the discursive feature of a conversation, conversation initiation and ending, number of pauses or hesitations by each gender, depicted in the scripts by '...' or 'Um' ..., and number of apologies by each gender, as a sign of subordination, are studied in each conversation. In order to have a cultural look at conversations the relationship between female and male character is derived from each conversation.

There were 22 cross gender conversations in ILI series which is coded as group 1, and 76 cross gender conversations in Interchange series which is coded as group 2. All the collected data are tabulated (see Appendix A) and analyzed by SPSS 11.5. The approach taken for data analysis and the results are represented in the next chapter.

\section{DATA ANALYSiS AND RESUlts}

This part deals with the second research question. The EFL teachers' perceptions were studied through a questionnaire and the results would be statistically analyzed using SPSS 11.5.

\section{A. Participants}

A total of 30 EFL teachers, 15 female and 15 male teachers, from Pardis-e-Goldis language institute in Tabriz were randomly selected to participate in this study. Their teaching experiences vary from 1.5 years to 21 years. Their minimum academic education in ELT was Bachelor of Arts (BA) in TEFL or English literature with a local background of TTC following which they had been certified to teach at the institute. Besides, all had the experience of teaching to both male and female students.

\section{B. Procedures}

A questionnaire containing 34 questions, 3 of which are demographic questions and are not included in the analysis, was prepared (see Appendix B). Question 1 asks the participant's gender and questions 5 to 34 are 'Likert scale' items on a 1-5 scale. These 30 items evaluate teachers' knowledge, attitude and practice on gender representation in the textbooks. In order not to give hints to the participants the items are distributed in the questionnaire (see Appendix $\mathrm{C}$ for classified items). To find out whether the questionnaire is reliable or not the 'test-retest' approach was administered. "Test-retest reliability is usually estimated by administering the same test twice to a group of subjects and then calculating a correlation coefficient between the pairs of scores from the two administrations" (Brown, 1988, p.99). 10 of the participants answered to the questionnaire twice within a week and the correlation coefficient was calculated between two administrations for each item. Among 30 items, items 30 and 33 did not pass the correlation evaluation with correlation coefficient of 0.37 and 0.59 respectively. The two items were simply excluded and the new questionnaire was administered to the participants (see Appendix D).

After data collection, the descriptive statistics are calculated for each group and the data are examined in terms of following a normal distribution using SPSS. By doing One-Sample Kolmogorov-Smirnov test for the data it turns out that they do not represent a normal distribution. So, the non-parametric approaches will be taken in order to analyze data.

Before data analysis it is good to have a look at descriptive statistics of the data. In ILI series, there are 22 cross gender conversations and 44 same gender conversations; while in Interchange series there are 76 cross gender conversations and 21 same gender conversations. These are illustrated in figures 4.1 and 4.2 and Table 4.1.

In ILI series the mean of word count for females and males are 54.91 and 60.32, respectively. As is seen word count mean for males is greater than that for females. In the analysis it will be seen whether this difference is significant or not. In Interchange series the word count mean for females and males are 60.25 and 55.76. (Table 4.2)

TABLE 4.1

FREQUENCIES AND PERCENTAGE OF CROSS GENDER AND SAME GENDER CONVERSATIONS IN ILI AND INTERCHANGE SERIES

\begin{tabular}{|l|l|l|l|l|}
\cline { 3 - 5 } \multicolumn{2}{c|}{} & $\begin{array}{l}\text { Cross Gender } \\
\text { Conversations }\end{array}$ & $\begin{array}{l}\text { Same Gender } \\
\text { Conversations }\end{array}$ & Total \\
\hline \multirow{2}{*}{ ILI Series } & $\mathrm{N}$ & 22 & 44 & 66 \\
\cline { 2 - 5 } & Percent & 33 & 67 & 100 \\
\hline $\begin{array}{l}\text { Interchange } \\
\text { Series }\end{array}$ & $\mathrm{N}$ & 76 & 21 & 87 \\
\cline { 2 - 5 } & Percent & 78 & 22 & 100 \\
\hline
\end{tabular}

TABLE 4.2

THE MEAN OF WORD COUNTS IN ILI AND INTERCHANGE SERIES FOR FEMALE AND MALE CHARACTERS

\begin{tabular}{|l|l|l|}
\cline { 2 - 3 } \multicolumn{1}{c|}{} & Word Count Mean \\
\cline { 2 - 3 } \multicolumn{1}{c|}{} & Females & Males \\
\hline ILI Series & 54.91 & 60.32 \\
\hline Interchange Series & 60.25 & 55.76 \\
\hline
\end{tabular}


The word count mean for females is greater than that of males. By comparing male and female word count means in two series it turned out that they were very slightly different. The significance for these differences is examined through statistical analyses as well.

First NH1 was being examined. In order to compare female and male word count means of the two independent series and see whether the differences are significant, 'independent-samples T-test' is a good aid. As the data did not follow a normal distribution, the non-parametric counterpart for independent-samples T-test which is 'Mann-Whitney $\mathrm{U}$ test' came in handy. By applying Mann-Whitney U test to the female word count mean in the both of the series, the pvalue was 0.627 which is greater than 0.05 and this means that the difference between two series in terms of female word count mean is not significant. The same test was applied to the male word count mean in both series and the derived p-value was 0.848 which is greater than 0.05 and therefore the difference between two series is not significant in terms of male word count mean.

In order to examine whether each series represented imbalance in terms of gender, 'paired-samples T-test' should have been applied to female and male word count means in each group. As the data were not normally distributed, the non-parametric counterpart for paired-sample T-test which is 'Wilcoxon signed rank test' was applied to data in each group. By applying Wilcoxon test to female and male word count means in ILI series, the derived p-value was 0.961 which is greater than 0.05 and therefore the difference between female and male word count means in ILI series was not significant and this series was not biased in favor of any gender. The same test was applied to both means in Interchange series and the derived p-value was 0.171 which is greater than 0.05 , so as well as ILI series, the Interchange series did not contain gender bias. In other words, the null hypothesis NH1 is supported and there is no significant difference between two series in terms of gender bias in favor of either gender and none of the series represent gender bias either.

In order to find out whether there are any kinds of imbalance in discourse features of the textbooks in terms of gender or not, $\mathrm{NH} 2$ was established. Among the 22 cross gender conversations in ILI series the means for female and male pauses were 0.14 and 0.05 , respectively. For 76 cross gender conversations in Interchange series those of female and male pauses were 0.12 and 0.22 respectively. The means for female and male apology in ILI series were 0.23 and 0.14 and in Interchange series were 0.11 and 0.16 respectively (Table 4.3). Figure 4.4 illustrates them in bar diagrams.

TABLE 4.3

THE MEANS OF PAUSES OR HESITATIONS AND APOLOGIES IN ILI AND INTERCHANGE SERIES FOR FEMALE AND MALE CHARACTERS

\begin{tabular}{|l|l|l|l|l|}
\cline { 2 - 5 } \multicolumn{1}{c|}{} & \multicolumn{2}{l|}{ Mean of pauses or hesitations } & \multicolumn{2}{l|}{ Mean of apologies } \\
\cline { 2 - 5 } & Females & Males & Females & Males \\
\hline ILI Series & 0.14 & 0.05 & 0.23 & 0.14 \\
\hline Interchange Series & 0.12 & 0.22 & 0.11 & 0.16 \\
\hline
\end{tabular}

As the variables were not normally distributed (Kolmogrov-Smirnov Test result), Mann-Whitney U test and Wilcoxon signed ranks test will be used for inter- and intra-series analyses, respectively. By applying Mann-Whitney U test to the mean of females and males pauses and apologies, the p-values were $0.822,0.25,0.098$, and 0.988 for female pauses, male pauses, female apologies and male apologies, respectively. As all these p-values are greater than 0.05 , the differences between means are not significant and the observed differences are by chance. By applying Wilcoxon signed ranks test to the means of female and male pauses and apologies in each series separately, the p-values for pauses and apologies in ILI series were 0.317 and 0.414 and for pauses and apologies in Interchange series were 0.284 and 0.415 respectively. As all these p-values are greater than 0.05 the observed differences are not significant and none of the series are imbalanced in gender representation in terms of these discourse features relatively.

The other discursive feature which is studied here is the initiation and ending of a conversation. Table 4.4 shows the frequencies of the two variables in each series.

TABLE 4.4

FREQUENCIES OF FEMALE AND MALE CONVERSATION INITIATION AND ENDING IN EACH SERIES

\begin{tabular}{|l|l|l|l|l|}
\cline { 2 - 5 } \multicolumn{1}{c|}{} & Initiation & Ending & Male \\
\cline { 2 - 5 } \multicolumn{1}{c|}{} & Female & Male & Female & 14 \\
\hline ILI Series & 10 & 12 & 8 & 44 \\
\hline Interchange Series & 31 & 45 & 32 & 4 \\
\hline
\end{tabular}

It is derived from the table that the numbers of males' conversation initiation and males' conversation ending were greater than those of females in both series, but whether this difference was significant or not was the most crucial question here. To find out this the 'Chi-Square test' had be applied to the data. By performing Chi-Square test, it turned out that the p-values for conversation initiation and conversation ending, for two series, were 0.696 and 0.629 , respectively. Both calculated p-values were greater than 0.05; so the differences were not significant and two series could be considered equivalent in terms of conversation initiations and endings for both genders.

The tests performed on the pauses, apologies and conversation initiations and endings supported NH2 and this means there were no significant differences between two series in terms of discursive features. 
When looking at the relationships in both series, it turned out that in ILI series, female and male characters in conversations were mostly relatives (husband and wife) or they had a customer / service provider relationship in which the female character was always the customer.

After the questionnaire was administered to the participants and the answers were elicited, the collected data were tabulated using SPSS 11.5 and means of each category and the mean of questionnaire were calculated for each participant. Now each participant had 4 score, i.e. K_MEAN, A_MEAN, P_MEAN, and Q_MEAN representing means of knowledge, attitude, practice, and Questionnaire score, respectively. The statistical analyses would be done on these four scores. The means and SDs of the data are shown in Table 4.5 and Table 4.6.

TABLE 4.5

MEANS AND STANDARD DEVIATIONS OF SCORES FOR FEMALE TEACHERS

\begin{tabular}{|c|c|c|c|c|}
\hline & K_MEAN & A_MEAN & P_MEAN & Q_MEAN \\
\hline Valid N & 15 & 15 & 15 & 15 \\
\hline Mean & 3.97 & 3.16 & 3.38 & 3.47 \\
\hline Std. Deviation & 0.36 & 0.47 & 0.32 & 0.31 \\
\hline
\end{tabular}

TABLE 4.6

\begin{tabular}{|c|c|c|c|c|}
\hline \multicolumn{5}{|c|}{ MEANS AND STANDARD DEVIATIONS OF SCORES FOR MALE TEACHERS } \\
\hline & K_MEAN & A_MEAN & P_MEAN & Q_MEAN \\
\hline Valid N & 15 & 15 & 15 & 15 \\
\hline Mean & 3.37 & 2.89 & 3.28 & 3.16 \\
\hline Std. Deviation & 0.48 & 0.41 & 0.59 & 0.41 \\
\hline
\end{tabular}

As are seen the means of females scores were greater than those of males scores and the attitude score is less than the others for both females and males. Besides, males' scores were more dispersed than females' scores. The diagram in figure 4.5 illustrates the data better.

Before conducting any statistical analyses, it was compulsory to evaluate the data in terms of being normally distributed. By applying One-Sample Kolmogorov-Smirnov test it turned out that the data followed a normal distribution therefore in order to compare means, Independent samples T-test will be conducted.

In order to see whether the differences between means for females' and males' scores were significant, Independent samples T-test is applied to the means in both females and males groups. By conducting T-test using SPSS 11.5, the pvalues for four variables are as the table below.

TABLE 4.7

P-VALUES FOR KNOWLEDGE, ATTITUDE, PRACTICE, AND QUESTIONNAIRE MEANS

\begin{tabular}{|l|l|l|l|l|}
\hline & K_MEAN & A_MEAN & P_MEAN & Q_MEAN \\
\hline p-value (2-tailed) & 0.001 & 0.118 & 0.566 & 0.029 \\
\hline
\end{tabular}

P-values for knowledge and questionnaire were less than 0.05 and therefore the observed mean differences were significant in these two cases and so female teachers' knowledge and overall perception can be considered more than those of male teachers' in this subject -matter.

In order to evaluate the go-togetherness of knowledge, attitude and perception of teachers, a Pearson correlation test is conducted between $\mathrm{K} \_$MEAN and A_MEAN, K_MEAN and P_MEAN, and A_MEAN and P_MEAN. The correlation coefficients are as in table 4.8.

TABLE 4.8

CORRELATION COEFFICIENTS FOR KNOWLEDGE, ATTITUDE, AND PRACTICE MEANS

\begin{tabular}{|c|c|c|c|}
\hline & K_MEAN*A_MEAN & K_MEAN*P_MEAN & A_MEAN*P_MEAN \\
\hline Pearson Correlation Coefficient & 0.535 & 0.421 & 0.636 \\
\hline p-value (2-Tailed) & 0.002 & 0.020 & 0.000 \\
\hline
\end{tabular}

As is shown in the table, correlations are significant and among all the correlation coefficient between A_MEAN and P_MEAN is greater than the others so these two are the most correlated variables. This means that teachers' practice is more related to their attitude than their knowledge.

\section{CONCLUSION AND DisCUSSION}

Research Question 1: Do the cross-gender conversations of EFL textbooks used in Iranian outside school English courses portray any kind of imbalance in gender representation quantitatively and in terms of some discourse features?

Looking back at the results of part 1 it is obvious that the ratio of cross gender conversations to same gender conversations in Interchange series is far greater than that of ILI series. Besides in ILI series the relationship between males and females in the conversations are of relative (mostly spouses) kind or a costumer / service provider kind which can be considered a cultural bias in the textbook. On the other hand, the women in the conversations are the costumers and men are the service providers. From this point of view ILI series has a traditional stereotypical presentation of women; being a wife or daughter or a house maker doing shopping, etc. which is in contrast with women's stance in Iranian society. This is in line with what Ansari and Babaii (2003) concluded from their study about gender 
representations in Right Path to English I and II. (See also Dominiguez, 2004, Law and Chan, 2004 \& Florence, 2004) that showed stereotypical representation of genders.

Results indicated that no differences were detected regarding word count, frequency of pauses, hesitations, apologies, and initiation and ending patterns. The word count was performed in order to see whether any of the series are biased in favor of either gender or not. Although descriptive results showed a difference between females' words per conversations and that of males, and ILI Series can be considered as having imbalance in gender representation in favor of males and Interchange Series in favor of females, the statistical analysis did not confirm this difference as true. Although comparing these results to those of Harashima (2004), Johansson and Malmsjö (2009), Florence (2004), and Jones, Kitetu, \& Sunderland (1995), the results of this study goes along with Jones et al. (1995) and others reported biased textbooks in terms of gender representation in conversations.

The last part which dealt with the firstness of characters in the conversations and its ending showed the following results. In both series, males won the ground; the number of the times males initiated a conversation and ended it was greater than those of women's. The result partly goes with that of Jones et al. (1995), but the difference observed was not significant.

Although it was predicted by the author that ILI Series, in contrast to Interchange Series, may contain imbalance in gender representation, and descriptive analyses confirms it, the result is far unpredictable. The insignificances observed for the differences can be due to the fact ILI Series are adapted from other original EFL/ESL textbooks and although are adapted to the Iranian culture, it still carries the features of original books.

Research Question 2: How do the teachers, who use these textbooks, think of the representation of gender?

By comparing the scores calculated for each teacher and their means (illustrated in Figure 3.5), it is seen that females have better overall perception about gender representation in the textbooks. But when the means are compared through statistical devices, it turns out that only the differences between the means of knowledge and overall questionnaire are significant. This shows that female teachers' knowledge in the issues concerning gender representation is higher than that of male teachers'. The difference and significance observed for the questionnaire scores can be due to those of knowledge as questionnaire score is related to the other three scores. It can be derived from the result that raising the teachers' knowledge changes their perception about gender representation in the textbooks. As Erden (2009) showed, the education of teachers has a great influence on their awareness about gender issues in the classroom and Chavez (2001) stated that as teachers become aware of gender imbalance in the textbooks they can mediate the content of the book in the way that it is less harmful.

By doing correlational tests on the means two by two, it turned out that teachers' practice is related to their attitude than their knowledge. It shows that teachers' belief system plays a great role in their classroom behavior. So as it is mentioned that the education of teachers improves their overall perception about the subject matter, this education should be in the way that it changes the attitude and belief system of the teachers.

Judging from the results above, we understand that, although improves are seen, still there are a big gap in gender representation studies in Iran. Our results about gender representation in textbooks, depicted in chapter 3, show that although the differences observed between two series are insignificant, still differences are seen and ILI Series, especially in terms of stereotypical representation can be considered imbalanced in gender representation. From the firstness point of view, again, in spite of insignificant differences, both series are in favor of males and teachers should consider this in their teaching that they can mitigate it by changing the roles, or giving opposite sex roles to the students, or taking other policies according to their creativity. What is obvious here is that the textbooks still need teachers' mediation as Chavez (2001) described. As some discursive features are studied here (i.e. number of pauses and hesitations, number of apologies and conversation initiation and ending) shows males and females status from authors' view, teachers should be aware if they consider bias to the disadvantage of either gender. Besides because conversations carry a high stance in communicative language classroom, the more teachers become aware of their imbalance in terms of gender representation, the more beneficial their teaching would be. On the other hand teachers should raise students' awareness about this subject when seen in the books in order to reduce the impacts of this imbalance. It is good to be mentioned here that as ILI Series is not communicative and they totally have fewer conversations than Interchange series, teachers of these textbooks should be conscious about other parts of the textbooks (reading, vocabulary, grammar ...) which are not studied here.

The second part of our research, dealt with a KAP study, evaluating teachers' knowledge, attitude and practice, in terms of gender representation in the textbooks. The results showed that female teachers got better score than male teachers. It was actually predictable that females are concerned more than males in gender issues. Still as the differences between means are not significant in all three categories but in knowledge, it is implicated that both female and male teachers not only should increase their knowledge about this subject matter, but also should change their attitudes and classroom behavior accordingly. The correlation part of the study shows that teachers' practice is related to their attitude than their knowledge. The implication here is that the organizations, universities, and language institutes that are in charge of training language teachers, should have a program to teach gender issues to the up and coming teachers and should raise their awareness of imbalance in gender representations in the textbooks. 


\section{REFERENCES}

[1] Ansary, H., Babaii, E. (2003). Subliminal sexism in current esl/efl textbooks. Asian EFL Journal. http://www.asian-efljournal.com/march03.sub1.php (accessed 5/10/2009).

[2] Brown, H.D. (2000). Principles of language learning and teaching. New York: Longman.

[3] Brown, J. D., Rodgers, T. S. (2002). Doing second language research. New York: Oxford University Press.

[4] Brown, J. D. (1988). Understanding research in second language learning. Cambridge: Cambridge University Press.

[5] Cameron, D. (2005). Language, gender, and sexuality: Current issues and new directions. Applied Linguistics, 26.4, 482-502.

[6] Cameron, D. (2009). Sex/gender, language and the new biologism. Applied Linguistics 31.2, 173-192.

[7] Chavez, M. (2001). Gender in the language classroom. Boston: McGraw Hill.

[8] Davis, K. A., \& Skilton-Silvester, E. (2004). Looking back, taking stock, moving forward: investigating gender in TESOL. TESOL Quarterly 38.3, 381-404.

[9] Dominiguez, L. M. (2003). Gender textbook Evaluation. Unpublished M A Thesis, University of Birmingham, Birmingham, UK.

[10] Eckert, P. (2003). Language and gender in adolescence. In J. Holmes \& M. Meyerhoff (eds.), The handbook of language and gender. Oxford: Blackwell Publishing. 381-400

[11] Eckert, P., \& McConnell-Ginet, S. (1999). New generalizations and explanations in language and gender research. Language in Society 28, 185-201.

[12] Eckert, P., \& McConnell-Ginet, S. (2003). Language and gender. Cambridge: Cambridge University Press.

[13] Erden, F. T. (2009). A course on gender equity in education: Does it affect gender role attitudes of pre-service teachers? Teaching and teacher education 25, 409-414.

[14] Florence, M. A. Y. (2004). Gender in textbook dialogues: textual analyses and classroom practices. Unpublished M A Thesis, University of Hong Kong, Hong Kong.

[15] Freed, A. F. (1995). Language and gender. Annual review of applied linguistics 15, 3-22.

[16] Freed, A. F. (2003). Epilogue: Reflections on language and gender research. In J. Holmes \& M. Meyerhoff (eds.), The handbook of language and gender. Oxford: Blackwell Publishing, 669-721.

[17] Harashima, H.D. (2005). Sexual bias in an EFL textbook: A case study. In K. Bradford-Watts, C. Ikeguchi, \& M. Swanson (eds.) JALT 2004 conference proceedings. Tokyo: JALT.

[18] Holmes, J. (2006). Gendered talk at work. Oxford: Blackwell Publishing.

[19] Holmes, J., \& Meyerhoff, M. (2003). The Handbook of language and gender. Oxford: Blackwell Publishing.

[20] Holmqvist, P., \& Gjörup, L. (2006). The representation of gender and gender roles in English textbooks. Retrieved October 2011 from http://dspace.mah.se:8080/bitstream/2043/3426/1/representation\%20of\%20gender.pdf (accessed 11/10,2009).

[21] Howe, C. (1997). Gender and classroom interaction: A research review. Edinburgh: The Scottish Council for Research in Education (SCRE).

[22] Johansson, S., Malmsjö, K. B. (2009). Gender bias in EFL textbook dialogues. Könsfördelning i dialoger i engelska textböcker from

http://dspace.mah.se:8080/bitstream/handle/2043/8217/Gender \%20Bias\%20in\%20EFL\%20Textbook\%20Dialogues.pdf?seque nce $=1$ (accessed 10/10/2009).

[23] Jones, M. A., Kitetu, C., \& Sunderland, J. (1997). Discourse roles, gender and language textbook dialogues: Who learns what from John and Sally? Gender and Education 9.4, 469-490.

[24] Kirkpatrick, M. (2003). The Nature and nurture of gender. Psychoanalytic Inquiry 23, 558-571.

[25] Kobia, J. M. (2009). Femininity and masculinity in English primary school textbooks in Kenya. The International Journal of Language Society and Culture 28, 57-71.

[26] Law, K. W. K., \& Chan, A. H. N. (2004). Gender role stereotyping in Hong Kong's primary school Chinese language subject textbooks. AJWS 10, 49-69.

[27] McElhinny, B. (2003). Theorizing Gender in sociolinguistics and Linguistic Anthropology. In J. Holmes \& M. Meyerhoff (eds.), The Handbook of Language and Gender. Oxford: Blackwell Publishing, 21-42.

[28] Özdoğru, A. A., Aksoy, G., Erdoğan, N., \& Gök, F. (2004). Content analysis for gender bias in Turkish elementary school textbooks. Proceedings of the sixteenth annual Ethnographic and Qualitative Research in Education conference. http://www.albany.edu/eqre/papers/39EQRE.pdf (accessed 5/10/2009).

[29] Sadker, M., Sadker, D. (1994). Failing at fairness: How our schools cheat girls. Toronto: Simon \& Schuster Inc.

[30] Sano, F, Lida, M. , \& Hardy, T. (2001). Gender representation in Japanese EFL textbooks. PAC3 at JALT2001 Proceedings. 899-906. Retrieved August 2010 from http://jaltpublications.org/archive/proceedings/2001/899.pdf (accessed 5/10/2009).

[31] Seliger, H.W., \& Shohamy, E. (1989). Second language research methods. Oxford: Oxford University Press.

[32] Sunderland, J. (2000a). Research into gender in language education: lingering problems and new directions. The Language Teacher 24.7, 8-10. from http://www.jalt publications.org/tlt/articles/2000/07/sunderland (accessed 11/6/2011).

[33] Sunderland, J. (2000b). Issues of language and gender in second and foreign language education. Language Teaching 33, 203223.

[34] Sunderland, J. (2006). Language and gender: An advanced resource book. New York: Routledge.

[35] Sunderland, J., Cowley, M., Rahim, F. A., and Leontzakou, C., Shattuck, J. (2000). From bias 'in the text' to 'teacher talk around the text': an exploration of teacher discourse and gendered foreign language textbook texts. Linguistics and Education $11.3,251-286$.

[36] Swann, J. (2005). Schooled Language: Language and Gender in Educational settings. In J. Holmes \& M. Meyerhoff (eds.), The handbook of language and gender. Oxford: Blackwell Publishing. 624-644.

[37] Weatherall, A. (2002). Gender, language and discourse. Sussex: Routledge. 
Massoud Yaghoubi-Notash holds a PhD in TEFL from the University of Tabriz, Tabriz, Iran. He is currently an assistant professor in the field teaching at undergraduate and post-graduate levels. He has published several articles in international journals and presented papers in conferences. His areas of interest include gender and ELT, task-based language teaching, and ESP/EAP.

Elmira Kooshavar holds a B.Sc. degree in Electrical Engineering from the University of Tabriz, Tabriz, Iran. She has continued her studies in TEFL at the Payam-e-noor University of Tehran, Iran. She is a part-time teacher at institutes and University of Medical Sciences. Her areas of interest include bilingualism, gender issues and ESP/EAP. 